\title{
Primeiro relato de Myrothecium roridum em mucucizeiro no Pará
}

\author{
Tathianne Pastana de Sousa Poltronieri ${ }^{1}$; Ruth Linda Benchimol²; Jaqueline Rosemeire Verzignassi ${ }^{3}$; Luiz Sebastião \\ Poltronieri ${ }^{2}$
}

${ }^{1}$ Departamento de Fitopatologia e Entomologia, Instituto de Biologia, Universidade Federal Rural do Rio de Janeiro, CEP 23890-000, Rio de Janeiro, RJ. ${ }^{2}$ Embrapa Amazônia Oriental, Tv. Enéas Pinheiro, S/N, CEP 66095-100, Belém, PA. ${ }^{3}$ Embrapa Gado de Corte, Avenida Rádio Maia, 830, CEP 79106-550, Campo Grande, MS.

Autor para correspondência: Jaqueline Rosemeire Verzignassi (jaqueline.verzignassi@embrapa.br)

Data de chegada: 11/11/2011. Aceito para publicação em: 17/09/2012.

O Brasil tem grande variedade de frutos que apresentam sabor exótico e grande potencial econômico. O murucizeiro (Byrsonima crassifolia (L.) Rich.) é uma espécie frutífera nativa da Amazônia, com ampla distribuição geográfica no território brasileiro, com fruto de forma arredondada e coloração alaranjada, e sendo consumido principalmente na forma de sucos, doces e licores. Pertencente à família Malpighiaceae, várias espécies do gênero Byrsonima são conhecidas pela utilização de seus frutos na alimentação, como também pelo seu uso medicinal. Estudos dos extratos das raízes e troncos do murucizeiro têm demonstrado suas atividades antimicrobiana, tripanomicida e antiespasmódica. Em área experimental da Embrapa Amazônia Oriental, foram encontradas plantas de murucizeiro cujas folhas apresentavam manchas areoladas, com coloração parda e halo escuro Figura (1A). Amostras de folhas com os sintomas foram encaminhadas ao Laboratório de Fitopatologia da mesma Unidade da Embrapa para a identificação do agente causal. Procedeu-se o isolamento em meio ágar-água e as colônias obtidas do isolamento foram multiplicadas em BDA $\left(26^{\circ} \mathrm{C}\right.$, luz fluorescente e fotoperíodo de $\left.12 \mathrm{~h}\right)$. Observações ao microscópio óptico permitiram a identificação do fungo Myrothecium roridum Tode ex Fr. O fungo forma esporodóquios (Figura 1B), algumas vezes sinematosos, com até $700 \mu \mathrm{m}$ de diâmetro. Os conídios apresentavam forma de bastão, às vezes elipsóides, com as extremidades comumente arredondadas, hialinos a levemente oliváceos, medindo de 4,5-7,3 x1,5-2 $\mu \mathrm{m}$ (Figura 2). Testes de patogenicidade foram efetuados em folhas sadias destacadas previamente feridas, inoculadas com discos de cultura contendo estruturas do fitopatógeno e submetidas à câmara

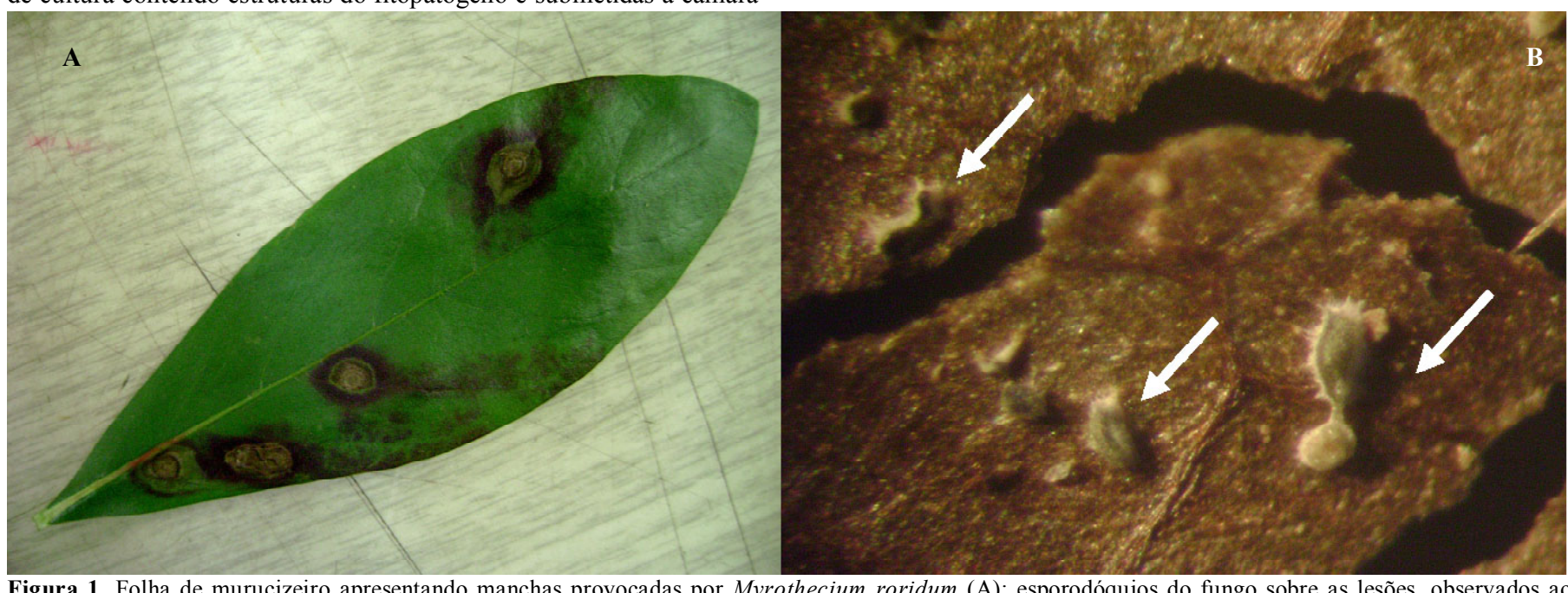

Figura 1. Folha de murucizeiro apresentando manchas provocadas por Myrothecium roridum (A); esporodóquios do fungo sobre as lesões, observados ao microscópio estereoscópico (B). úmida por $48 \mathrm{~h}$. Após cinco dias, as folhas apresentaram os mesmos sintomas encontrados no campo. Efetuou-se o reisolamento do fungo, confirmando-se a sua patogenicidade. Myrothecium roridum foi detectado no Pará em juta (Corchorus capsularis L.), acerola (Malpighia glabra L.) e em noni (Morinda citrifolia L.). Este é o primeiro relato de $M$. roridum em murucizeiro no Pará e, provavelmente, no Brasil e no mundo.

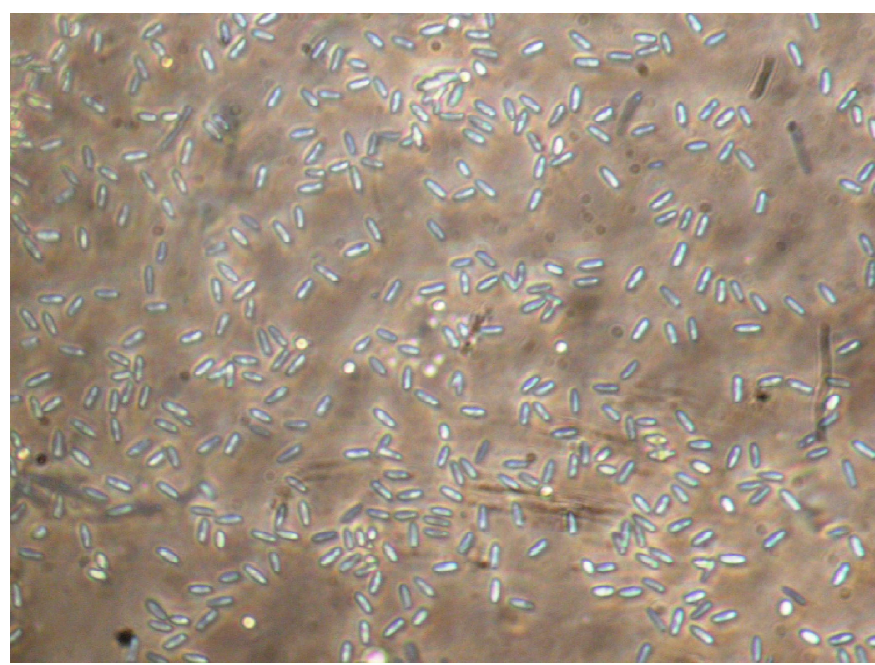

Figura 2. Conídios de Myrothecium roridum observados ao microscópio óptico 